\title{
A prática do desenvolvimento da liderança em instituição financeira.
}

\section{Resumo}

O objetivo do artigo é avaliar os programas de liderança de uma instituição financeira multinacional sediada no Brasil quanto ao autodesenvolvimento, gestão de equipes e alinhamento à estratégia e modelo de gestão da organização. A pesquisa foi conduzida por meio de revisão bibliográfica sobre liderança e sobre política e do exame de material do banco em 2010. A análise dos programas de capacitação da instituição mostrou a complementaridade entre as diferentes contribuições teóricas sobre o tema.

Palavras chave: Liderança, Instituição Financeira, Autodesenvolvimento

\section{The practice of leadership development in a financial institution}

\begin{abstract}
This paper aims to evaluate the leadership programs of a multinational financial institution headquartered in Brazil regarding its self-development, team management and alignment to the strategic and management model of the organization. The research was conducted byreviewing the literature onleadershipandon policyaswellasthe examination of the bank's material in 2010. The analysis of this institution's training programs showed the complementarities between the different theoretical contributions on the subject
\end{abstract}

Key-Words: Leadership, Financial Institution, self-development

\footnotetext{
1 Administradora, Mestre em Administração pela PUC/SP.

${ }^{2}$ Economista, Professora Titular do Departamento de Economia e do Programa de Estudos Pós-Graduados em Administração da PUC/SP.
} 
Maruyama, Amorim

Páginas 20-32

\section{Introdução}

O estudo do tema atrai a atenção tanto de pesquisadores e empreendedores quanto de líderes e liderados. A literatura é vasta e conhecida, há controvérsia e, em nosso entendimento, também complementaridade entre os diferentes enfoques. No âmbito do consenso, um ponto se destaca: liderança é fenômeno do grupo, de relações entre pessoas; as características da relação entre líder e liderado por sua vez, são muitas, da influência ao controle explícito. No presente artigo, a revisão da literatura não será exaustiva, apenas suficiente para amparar as análises e ressaltar que, enquanto autores se propõem excludentes, as práticas podem ser conciliatórias.

As primeiras abordagens teóricas (no início do século XX) estudaram o fenômeno a partir das características individuais, objetivando uma taxonomia de traços pessoais e motivações para descrever o "tipo ideal" do líder. A classificação revelouse impossível, tantas eram as possibilidades de tipos e motivações. As pesquisas posteriores procuraram classificar as tarefas típicas dos líderes, abrindo o vasto campo do treinamento ou desenvolvimento para a liderança (Bergamini, 1994). Ora, a continuidade dos estudos logo revelou que a eficácia das ações (ou tarefas) do líder e particularmente dos estilos de executá-las dependia fortemente do contexto. Levada às últimas consequências, a supervalorização do contexto criou a máxima curiosa que o líder emerge do contexto e portanto, todos os indivíduos em uma organização podem ser líderes, independentemente da hierarquia ou função!

As três principais abordagens do fenômeno da liderança (dos traços, dos comportamentos e da situação) sucederam-se no tempo e é cômodo descrevê-las nessa ordem. Porém, a ordem escolhida não significa que a liderança situacional tenha resolvido os problemas teóricos e práticos das anteriores e muito menos, que seja superior às antecessoras.

O principal problema metodológico, não superado pelas três principais abordagens, está na origem do fenômeno: a tautologia na definição de liderança, a circularidade que procura definir o líder pelo exercício da liderança, e a liderança pelo que o líder faz ou é, nos mais variados contextos. Se o fenômeno não está definido, recomendamos não usar a expressão "teoria" para discuti-lo, o que por sua vez, não reduz a importância dos estudos sobre liderança, assunto indiscutivelmente primordial para a gestão de pessoas nas organizações. O importante conhecimento acumulado sobre liderança também pode ser compreendido como um conjunto de práticas e reflexões. Uma possiblidade de lidar com o fenômeno é recorrer ao campo de estudos das teorias sobre política e analisar a liderança como exercício de poder nas organizações (Amorim. Martins, 2007) - debate que escapa aos limites do presente artigo.

O artigo resulta de pesquisa realizada para a elaboração de dissertação de mestrado, realizada com apoio dos dados coletados no Grupo de Pesquisa Regulamentação Econômica e Estratégias Empresariais, da PUC/SP (o grupo tem como objeto o conjunto de setores produtores de bens públicos, entre esses, o financeiro). A metodologia consistiu em revisão da literatura sobre liderança e política e análise da documentação dos programas de liderança desenvolvidos por uma instituição financeira entre 2007/2010. O trabalho está dividido em quatro partes: caracterização da instituição financeira e descrição dos programas de liderança, síntese das principais contribuições sobre liderança, apresentação dos resultados da pesquisa e considerações finais. 


\section{PUC-SP}

\section{A instituição}

A organização em estudo atua no segmento financeiro. Foi fundada na Europa em 1857 e está presente na Espanha, Portugal, Alemanha, Reino Unido, Brasil, México, Chile, Argentina e Estados Unidos. Opera em escala global, nas divisões de banco de varejo, atacado, gestão de ativos, seguros e meios de pagamento. Possuem 169 mil funcionários que atendem cerca de 90 milhões de clientes em 13.600 agências espalhadas pelos países citados.

No Brasil, está presente desde 1957, atuando em todos os segmentos do mercado financeiro com uma rede de 3.600 agências e 18.100 caixas eletrônicos. Em 2010, a carteira foi de 10 milhões de clientes ativos, a operação no Brasil contava com aproximadamente 52 mil funcionários, respondeu por mais de $20 \%$ do lucro líquido do grupo e $53 \%$ de lucro líquido na América Latina. Quanto à participação de mercado relativamente ao número de agências, foi maior na região sudeste (15\%), seguida do sul $(9 \%)$, nordeste $(7 \%)$, centro oeste $(5 \%)$ e norte $(5 \%)$.

Os processos de aquisições, fusões e crescimento orgânico aumentaram a participação no mercado em vários segmentos e produtos, ampliando número de agências, resultados e reforçando a marca. Porém, devido à integração de áreas, principalmente administrativas, houve redução de quadro nas áreas operacionais e matriciais e o "congelamento" de novas contratações em determinadas funções e áreas ou a não reposição das vagas provenientes de desligamentos à pedido da organização ou por iniciativa do bancário (dados colhidos em 2010).

A instituição encerrou o programa de trainees, direcionando o investimento para uma plataforma aberta à sociedade para interação com jovens estudantes candidatos a estágio ou mesmo para interação de executivos do banco com o público visando direcionamento de carreira e ambientação na área financeira. A redução de pessoas gerou acúmulo de funções, responsabilidades e tarefas para os que permaneceram e um clima organizacional tenso, caracterizado pela instabilidade quanto ao emprego.

A crise econômica iniciada em 2009 levou a instituição a projetar na operação brasileira a expectativa de contribuir mais intensamente com o resultado mundial. Isso intensificou diretamente a cobrança por aumento da contribuição financeira do Brasil. Daí medidas como elevação da meta para o lucro da operação e torná-la ainda mais rentável com número reduzido de pessoas, mudanças nos programas de remuneração variável e campanhas institucionais, além da relação entre orçamento aprovado e receita esperada tomar proporções ainda mais desafiadoras.

A instituição possui quatro segmentos de programas institucionais: Entrada (Becas e Formação em Riscos); Desenvolvimento (Mundo XXI e MBA Internacional), Corporativos (Futuros Diretivos e STEP) e Atratividade (Summer Job). Cada um atua em determinado público-alvo e com ênfase no reforço de cultura e formação de novos líderes da organização. Os programas de desenvolvimento de liderança vigentes estão divididos em três blocos: Gestão Corporativa do significado (representado pelo programa Ser Líder); Gestão das Relações (formado pelos programas Ser Gestor Básico, Ser Gestor I, Ser Gestor II e Ser Gestor III) e Autogestão (Mentoring e Coaching). Nosso trabalho analisa os principais cursos institucionais e de liderança do banco por meio dos conteúdos programáticos, público-alvo, carga horária e blocos de desenvolvimento.

O público dos treinamentos é formado pelos funcionários elegíveis em posição de liderança - cargo de gerente geral, gerente de atendimento da rede de agência, gerente de área da matriz, superintendentes, gerentes executivos e acima. De 
acordo com os dados do banco de 2007 , $40 \%$ dos funcionários estão na faixa etária entre 26 e 35 anos, mais da metade da amostra (52\%) são casados e sem filhos e aproximadamente $70 \%$ tem nível superior completo e um quarto destes também tem pós-graduação, mestrado ou doutorado. Nos cargos de liderança, considera-se que mais de $38 \%$ do total de funcionários do grupo no Brasil está em posições de liderança e mais de $55 \%$ destes são elegíveis aos programas aqui estudados.

\section{Da liderança}

Limongi-França e Arellano (2002) apresentam uma síntese das contribuições de vários autores sobre o tema liderança, ora no campo dos traços, ora dos comportamentos, com maior ou menor ênfase ao contexto. De acordo com as autoras, o indivíduo não é líder apenas pela posse de certa combinação de traços, mas também pela capacidade de atender às expectativas dos liderados e da cúpula da organização. No rol das funções, um conjunto possível trata de pôr em funcionamento uma política, criar uma estratégia, mobilizar equipes e fazer alianças criando uma cultura de empresa que seja motivadora.

As tentativas de organizar as diferentes definições de vários autores apresentadas em Bergamini (1994) são ilustrativas quanto às dificuldades metodológicas aludidas na Introdução deste artigo: (1) comportamento de um indivíduo quando está dirigindo as atividades de um grupo em direção a um objetivo comum; (2) tipo especial de relacionamento de poder caracterizado pela percepção dos membros do grupo no sentido de que outro membro do grupo tem o direito de prescrever padrões de comportamento na posição daquele que dirige; (3) influência pessoal exercida por meio do processo de comunicação para atingir objetivo especifico; (4) interação entre pessoas na qual uma logra convencer as demais que seus resultados serão melhorados caso se comportem da maneira sugerida ou desejada; (5) incremento da influência sobre e acima de uma submissão mecânica com as diretrizes rotineiras da organização; (6) processo de influenciar as atividades de um grupo organizado na direção da realização de um objetivo.

Diante desse rol de definições (que está longe de ser exaustivo) e da premência das organizações em desenvolver lideranças, compreende-se a profusão de manuais e ofertas de consultorias, cuja face positiva é o empenho em resolver problemas objetivos a despeito dos limites metodológicos da chamada ciência normal. A face negativa é transformação perigosa de um fenômeno complexo com a liderança, em modelos simples, o chamado "to do".

Robbins (2005) propõe uma classificação útil para a discussão do conhecimento sobre liderança, divide-o em quatro grandes grupos: teoria dos traços, teorias comportamentais, teorias contingenciais e contemporâneas. A expressão "contemporâneas" não deve sugerir ao leitor que as mais recentes contribuições sejam melhores que suas antecessoras.

\section{Teoria dos traços}

Os estudos sob a denominação de liderança, até a década de 40 , receberam a contribuição das pesquisas desenvolvidas pelos testes psicológicos (muito incrementados entre 1920 e 1950) que enfatizavam especialmente as qualidades pessoais do líder. Os líderes deveriam possuir certas características de personalidade especiais que responderiam pelo desempenho do papel de liderança. Líderes eram seres diferentes das demais pessoas por possuírem alguns traços de personalidade 
considerados como responsáveis não só por fazê-los emergir como líderes, como também por mantê-los em suas posições. Assim, líderes são natos, das características físicas, cerebrais e de personalidade.

Porém, os estudos feitos neste primeiro esforço de pesquisa empírica a respeito das características da personalidade do líder levaram a um resultado impossível de ser considerado em termos práticos. Por exemplo, uma revisão de 20 trabalhos nessa linha, feita no final dos anos 60 , identificou quase 80 traços de liderança, mas apenas cinco eram comuns a quatro ou mais estudos. Por volta dos anos 90 , depois de muitos estudos e análises, o máximo que se poderia dizer é que os sete traços seguintes pareciam diferenciar os líderes dos não-líderes: ambição e energia, desejo de liderar, honestidade e integridade, autoconfiança, inteligência, elevado auto monitoramento e conhecimentos relevantes para o trabalho. Mas a capacidade de prever a liderança a partir desses traços continua modesta (Robbins, 2005: 259).

Há quatro limitações importantes na "teoria dos traços": (1) não existe traço universal que possa prever a liderança em qualquer situação, na verdade, os traços parecem prever a liderança em situações seletivas; (2) traços preveem melhor o comportamento em situações "fracas" do que em situações "fortes" (3) as evidências são pouco claras quanto à separação de causa e efeito; (4) traços funcionam melhor para prever o surgimento da liderança do que para distinguir entre líderes eficazes e ineficazes, o fato de um indivíduo apresentar determinados traços e ser considerado um líder pelos demais não significa, necessariamente, que ele será bem-sucedido em liderar seu grupo para o alcance dos objetivos (Robbins, 2005).

\section{Teorias comportamentais}

O foco de análise migrou das características de personalidade para o comportamento, o líder deve definir-se pelo que faz e afinal, interessa identificar quais os comportamentos mais eficazes quanto ao controle - ou influência - dos liderados. No reino da ação, o líder não é nato, pois as pessoas podem ser treinadas (ou desenvolvidas) para a liderança.

O esforço de classificação dos comportamentos dos líderes remonta aos anos 50 , e foi tão estéril como o de classificar traços de personalidade. Porém, ainda que não completa, a classificação trouxe balizas oportunas para a compreensão das práticas ou estilos de liderança: os líderes orientados para pessoas ou para processos. Mostrou também que quanto mais complexa a atividade dos liderados, maior a eficácia do líder capaz de trabalhar adequadamente com a subjetividade das pessoas (motivações, significados simbólicos, expectativas, etc.) (Robbins, 2005).

As chamadas teorias comportamentais ou dos estilos de liderança trouxeram subsídios importantes para a gestão de pessoas e aproximaram-se de outro tema, a motivação. Se de um lado, a proximidade rendeu contribuições oportunas, de outro, levou autores (particularmente de magazines de negócios) a reduzir a liderança à motivação, e o líder a um tipo de "animador de torcida", com permissão para a metáfora. A principal fragilidade da abordagem do "estilos de liderança" é a desconsideração do impacto do contexto (ou situação) na eficácia do estilo.

\section{Teorias Contingenciais}

As teorias contingenciais, também conhecidas como situacionais, tiveram destaque na década de 1970 e exploraram as variáveis do entorno, sem no entanto, deixar de lado os diferentes tipos de comportamentos dos líderes. Pelo contrário, praticamente todas elas buscaram determinar padrões comportamentais expressos 
pelos mesmos quando considerados prontos a atingir o maior grau possível de eficácia em cada diferente situação. Autores como Fiedler, Hersey e Blanchard são os mais importantes expoentes da "liderança situacional".

Ora, se o contexto determina da eficácia da ação do líder, esse será tão mais competente quanto maior sua capacidade individual de adaptar-se e variar condutas. Vale lembrar que o tema adaptação dos sistemas autopoiéticos apresentava muito vigor década de 70, apoiado no sistemismo, na cibernética e ciências da cognição (Dupuy, 1996).

Hersey e Blanchard (1986) levaram o peso do contexto às ultimas consequências: a eficácia da liderança é dada pelos liderados, que em última instância, definem o estilo ideal do líder. Desenvolveram um modelo de liderança que vem conquistando seguidores entre diversos especialistas em desenvolvimento da administração e cujo foco repousa sobre os liderados. Vale a citação literal de Robbins (2005):

"A ênfase nos liderados, no que se refere à eficácia da liderança, reflete a realidade de que são eles que aceitam ou não um líder. Independentemente do que fizer o líder, a eficácia dependerá das ações de seus liderados. Essa é uma dimensão importante que foi menosprezada ou pouco enfatizada na maioria das teorias sobre liderança (Robbins, 2005: 266),"

De um lado, os autores aproximam-se Foucault (1979) ao enfatizar que poder é relação entre pessoas e por isso mesmo, pode variar indefinidamente de forma. De outro, tendem a empalidecer justamente o papel do líder, tornando-o coadjuvante no exercício do poder e portanto, reduzindo sua importância na liderança. O discurso de empalidecer o agente controlador é compreensível, faz parte da eficácia do poder escamotear o controle aos olhos dos controlados. Sennett (2002) explorou o ocultamento do poder nas organizações na conhecida obra "A corrosão do caráter". A versão de magazine das contribuições da liderança situacional autores é a ideia cândida do "líder servidor".

As chamadas teorias contemporâneas, nos limites do presente artigo, podem ser apresentadas apenas por seus títulos: teoria da troca, do caminho - objetivo, da liderança carismática, da liderança transacional. A leitura de Robbins (2005) dá um panorama oportuno ao leitor.

\section{Programas institucionais e de liderança}

A formação de liderança está dividida em programas institucionais e de liderança propriamente ditos. Examinamos os dois conjuntos por que o primeiro é condição para que os funcionários participem do segundo.

\section{Programas Institucionais}

A instituição possui quatro segmentos de programas institucionais: Entrada (Becas e Formação em Riscos), Desenvolvimento (Mundo XXX e MBA Internacional), Corporativos (Futuros Diretivos e STEP) e Atratividade (Summer Job). Cada um atuante em determinado público-alvo e com ênfase no reforço de cultura e formação de novos líderes da organização.

O primeiro bloco de programas de Entrada abrange dois treinamentos: Becas e Formação em Riscos. O primeiro objetiva identificar o melhor talento internacional, oferecendo formação prática especializada no sistema financeiro, contribuindo com a identificação de potenciais e futuros profissionais para o grupo em mais de trinta países onde o banco está presente. Como pré-requisitos, os profissionais devem ser formados entre 2008 e 2010 nos cursos de economia, administração de empresas, engenharias, física ou matemática, além de inglês e espanhol fluentes. 
O programa Formação em Riscos busca atrair e contratar jovens de alto potencial para desenvolver especialistas e futuros líderes para o segmento de riscos, no Brasil e exterior. Tem como pré-requisitos alunos cursando o último ano de faculdade nos cursos de engenharia, matemática, estatística, economia, administração e física das faculdades escolhidas: IME, ITA, UFSCAR, UNICAMP, USP, FGV. É necessário também inglês nível intermediário para avançado e espanhol desejável.

O segundo bloco de Programas de Desenvolvimento abrange dois programas com experiência internacional. O primeiro oferece a um grupo de profissionais a oportunidade de realizar um intercâmbio de até quatro meses, preferencialmente na mesma área de negócio, em um dos países onde o banco opera. O segundo é um MBA internacional realizado em escolas no exterior reconhecidas entre o grupo das 10 melhores segundo o ranking da Business Week ou Financial Times. O objetivo é dar oportunidade para profissionais reconhecidos e percebidos com potencial de desenvolvimento e prepará-los para assumir posições seniores de liderança no médio prazo das empresas do grupo. Como pré-requisito é necessário estar formado há pelo menos 2 anos em um curso de graduação, ter no mínimo 2 anos completos na organização, experiência de no mínimo 2 anos como gestor de pessoas, inglês fluente, cargo efetivo, histórico de desempenho e a indicação do gestor.

O terceiro bloco de Programas Corporativos é composto por Futuros Diretivos e STEP. O primeiro é um programa da Divisão América para desenvolver, mediante um programa de designações internacionais, um grupo de profissionais identificados segundo critérios exigentes, que tenham potencial para suprir as necessidades de Diretivos Corporativos do Grupo na América Latina. Como pré-requisitos é necessário ter idade entre 24 e 28 anos, nível superior completo preferencialmente com pósgraduação, mínimo de 2 anos de vínculo empregatício no grupo, histórico de boas avaliações, perfil e motivação para atuar nas áreas de negócios de varejo do grupo e inglês intermediário para avançado.

O STEP é um programa para o desenvolvimento de profissionais com potencial e talento para assumir posição diretiva a médio e longo prazo. O profissional participa e se beneficia de um plano de desenvolvimento que combina experiência prática em diversas áreas de negócio, com formação e acompanhamento presencial e a distância. Como pré-requisitos é necessário nível avançado em inglês e espanhol (classificatório), idade de 26 a 30 anos, mínimo de 3 anos de experiência profissional (externa e do grupo), superior completo (curso de pós-graduação são diferenciais importantes), histórico de avaliações destacadas de desempenho, mobilidade funcional e geográfica, funcionário que já exerça posição de gestão como coordenador, supervisor ou gerente.

O quarto bloco, de atratividade, busca identificar estudantes brasileiros nos cursos de MBA internacional em universidades consideradas top 10 - segundo ranking da Financial Times e Business Week. Como pré-requisito, devem estar cursando o $1^{\circ}$ ou $2^{\circ}$ ano de MBA internacional, com formação acadêmica anterior destacada, idade de 28 a 32 anos, alto potencial de desenvolvimento, perspectivas de carreira acelerada e perfil para mercado financeiro.

Conforme figura 1 , identifica-se pela descrição dos objetivos que, dos sete programas oferecidos para atrair talentos, desenvolver potenciais e reforçar cultura, quatro são voltados à identificação (por meio do processo seletivo do curso) e formação de novos e futuros líderes da organização. 
Figura 1

\begin{tabular}{|c|c|c|}
\hline Bloco - Institucionais & Programas & Objetivo \\
\hline \multirow[b]{2}{*}{ E ntrada } & Becas & $\begin{array}{l}\text { Identificar o methor talento internacional, oferecendo } \\
\text { formação prática especializada no Sis tema Financeiro, } \\
\text { contribuindo com a identificação de potenciais e futvros } \\
\text { profissionais para o grupo. }\end{array}$ \\
\hline & Formação em Riscos & $\begin{array}{l}\text { Busca atrair e contratar jovens de alto potencial para } \\
\text { desenvolver especialis tas e futuros lideres para o } S \text { esmento de } \\
\text { Riscos, no Brasil e Exterior. }\end{array}$ \\
\hline \multirow[b]{2}{*}{ Desenvolvimento } & Mundo XXX (nome do Banco) & $\begin{array}{l}\text { Oferecer vivência internacional através de intercâmbio de até } \\
\text { quatro meses, preferenciatmente na mesma área de negócio } \\
\text { que atua em um dos paises do grupo. }\end{array}$ \\
\hline & MBA Internacional & $\begin{array}{l}\text { Realizado en escolas no exterior reconhacidas entre o grupo } \\
\text { das } 10 \text { methores segundo o ranking da Business Week ov } \\
\text { Financial Ttmes, o objetivo é dar oportunidade para } \\
\text { profissionais reconhecidos e percebidos como potencial na } \\
\text { organizaç ào de se desenvolverem e arimorarem seus } \\
\text { conhecimentos de forma a prepará-los para assumir posiçöes } \\
\text { seniores de liderança no médio prazo das empres as do Grupo. }\end{array}$ \\
\hline \multirow[b]{2}{*}{ Corporatios } & Futuros Diretivos & $\begin{array}{l}\text { Desenvolver, mediante um programa de designações } \\
\text { internacionais, um grupo de profissionais identificados } \\
\text { segundo critérios exigentes, que tenham potencial para suprit } \\
\text { as necessidades de Diretivos Corporativos do Grupo na } \\
\text { Améric a Latina. }\end{array}$ \\
\hline & STEP & $\begin{array}{l}\text { Desenvolver de profissionais com potencial e talento para } \\
\text { assumir posição dirediva a médio e longo prazo. O profissional } \\
\text { participa e se beneficia de um plano de desenvolvimento que } \\
\text { combina experiência prátic em diversas áreas de negócio, } \\
\text { com formação e acompanhamento presencial e a distância. }\end{array}$ \\
\hline Atratividade & Summer Job & $\begin{array}{l}\text { Identificar estudantes brasileiros nos cursos de MBA } \\
\text { internacional en Universidades consideradas Top } 10 \text {. } \\
\text { segundo ranking da Financial Times e Business Week, vis ando } \\
\text { alavancar resultados na organização. }\end{array}$ \\
\hline
\end{tabular}

Fonte: elaboração das autoras com base nos documentos da instituição, 2011.

\section{Programas de desenvolvimento de liderança}

Os programas de desenvolvimento de liderança estão divididos em três blocos: gestão corporativa do significado (representado pelo programa Ser Líder), gestão das relações (formado pelos programas Ser Gestor Básico, Ser Gestor I, Ser Gestor II e Ser Gestor III) e autogestão (Mentoring e Coaching).

No programa Ser Líder, de carga horária maior e o único do bloco que trabalha gestão corporativa e do significado, os objetivos abrangem desenvolver líderes capazes de traduzir o modelo da instituição e expressá-lo no dia-a-dia, favorecendo

ReCaPe Revista de Carreiras e Pessoas São Paulo. V.02 n.03 Set/Out/Nov/Dez 2012 
o engajamento e a criação de valor presente e futuro para todos os públicos, autoconhecimento e conhecimento do modelo do banco. Reforça confiança, inovação e sustentabilidade associadas a geração de resultados que contribuam para que a operação Brasil torne-se destaque no setor e referência na sociedade. Possui uma duração de 18 meses, com carga horária total de 162 horas divididas em 60 horas de seminários interativos, 18 horas de trabalhos aplicativos, 24 horas de oficinas e encontros com CEOs, 24 horas de Círculo Colaborativo e 36 horas de processo de coaching. O público-alvo são funcionários com cargo de liderança dentro da organização, com nível hierárquico de gerente executivo e acima.

No bloco de gestão das relações, o primeiro da série de programas é o Ser Gestor Básico, criado para o público de novos gestores, cujo objetivo é fortalecer os gestores na utilização das ferramentas, políticas e práticas disponíveis no banco para a gestão do ciclo de vida do funcionário dentro da organização. Tem duração de 16 horas e o conteúdo abrange o papel do gestor, ambiente de trabalho, atração e seleção, contratação, benefícios, integração, ciclo de gestão da performance, ponto eletrônico, estabilidade, afastamentos, férias, movimentações, desligamento, alteração salarial, mérito e ações de desenvolvimento.

No programa Ser Gestor I, para gestores no início de função, o objetivo é ampliar o conhecimento dos participantes sobre gestão de pessoas e os principais impactos dessa função no dia-a-dia e consequentemente, nos resultados da organização. Com duração de 40 horas, o conteúdo compreende: processo de seleção e contratação de pessoas, conceito de competências e identificação das competências organizacionais, legislação aplicada ao ciclo de vida funcional, relações trabalhistas e sindicais, saúde ocupacional e qualidade de vida, papel e responsabilidades do gestor, comunicação assertiva, feedback, formulação de objetivos versus comprometimento da equipe e casos de desligamento (eficácia e dignidade).

No Ser Gestor II, para gestores até um ano na função, o foco é desenvolver habilidades deliderança e gerenciamento de pessoas, estimular o autodesenvolvimento, fornecer ferramentas de incremento das habilidades interpessoais, notadamente em estilos de liderança e demonstrar como o processo de gestão de pessoas está alinhado ao modelo de negócio do banco. Com carga horária de 16h, o conteúdo aborda o papel do líder, desafios frente aos stakeholders, estilos de liderança e impactos no ambiente, fontes de poder e táticas de influência, feedback, credibilidade e cultura, gerenciamento de pessoas.

Para os gestores de gestores, o Ser Gestor III, com 16 h de duração, busca construir e manter equipes de alto desempenho, exercitar o feedback e construir o plano de desenvolvimento da equipe de trabalho. No conteúdo, traz conceitos e características de equipes de alta performance, mapeamento de práticas positivas, mapeamento da equipe e construção de plano de ação, características do estilo treinador, percepção (janela de Johari), conceitos e práticas de feedback (simulações) e competências na função.

No bloco de autogestão há o Mentoring cujo objetivo é promover o engajamento a partir da reflexão sobre a interação com outro no desenvolvimento individual. $O$ programa possibilita o auto-desenvolvimento de acordo com necessidades individuais e abrir novas alternativas para estabelecer vínculos de desenvolvimento que não apenas o de gestor-funcionário. O público alvo de potenciais mentores é formado de gestor de pessoas com pelo menos quatro anos de experiência como líder, participante 
do workshop "Confiar para Construir" e do Programa "Ser Líder", pessoas que tenham passado por processos de coaching, mentoring ou tenha atividades extracurriculares e sejam reconhecidas pelo papel ativo no desenvolvimento de pessoas.

O público alvo de mentorados é formado por ex-participantes dos Programas de Desenvolvimento de Jovens Talentos como Futuros Diretivos, STEP, MBA Internacional e Trainees. Inclui mulheres, pessoas com deficiência e/ou interessadas no autodesenvolvimento e que estejam com a necessidade de melhorar o desempenho individual.

No coaching, o objetivo é possibilitar ao executivo reconhecer e alcançar seu pleno potencial e entender seu papel na organização, passando a encarar desafios com maior segurança, organizar equilibradamente a vida pessoal, associados à busca dos objetivos da empresa.

A figura 2 permite analisar como a instituição agrupa os programas de acordo com o tripé de autogestão, gestão das relações entre pessoas e gestão da estratégia. A figura também mostra como se organiza e direciona o investimento na formação e alinhamento da liderança com a atuação no modelo do banco.

\section{Figura 2}

\begin{tabular}{|c|c|c|c|c|}
\hline Bloce - L id era aça & Programas & Objetive & Carga Herá nia & Conterido \\
\hline $\begin{array}{c}\text { Gestäo Corporatival do } \\
\text { Significado }\end{array}$ & Ser Lider & 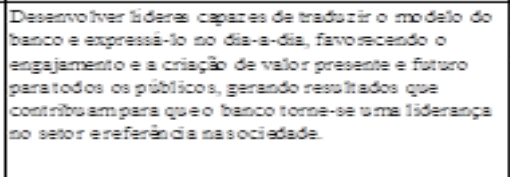 & $\begin{array}{l}\text { Dera,ĩo: } 18 \\
\text { meses. Total } \\
\text { boras: } 162 \mathrm{a}\end{array}$ & 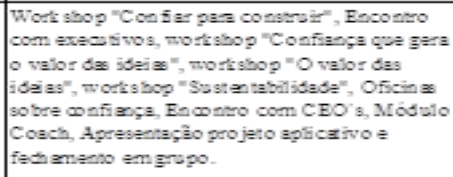 \\
\hline \multirow{4}{*}{ Ces tão das R elaçōes } & $\begin{array}{c}\text { SerGestor- } \\
\text { Básice }\end{array}$ & 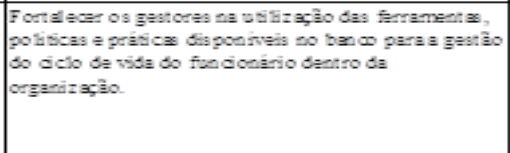 & 16 boras & 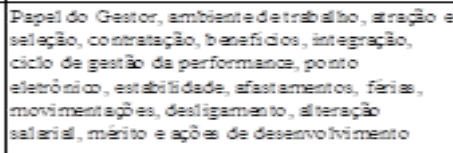 \\
\hline & Ser Cester I & 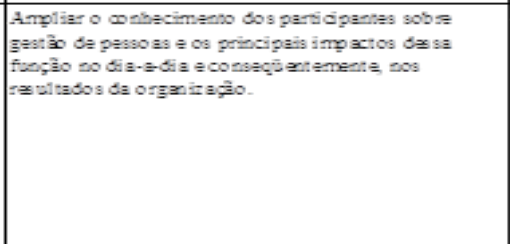 & 40 boras & 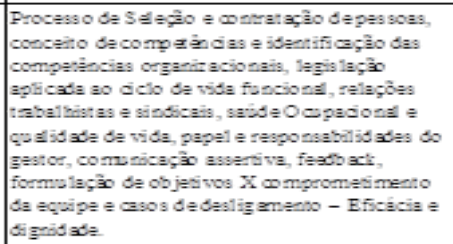 \\
\hline & SerGestorII & 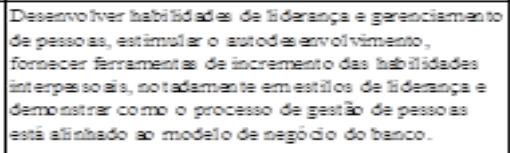 & $15 \mathrm{~s}$ & 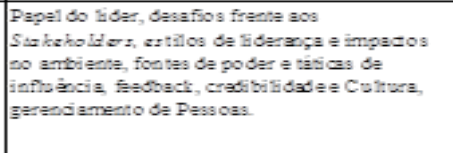 \\
\hline & Ser Cestor III & 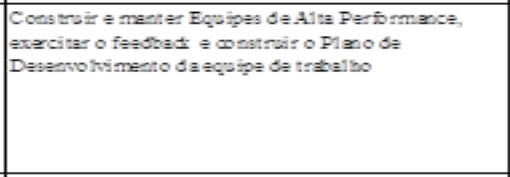 & $16 \mathrm{~b}$ & 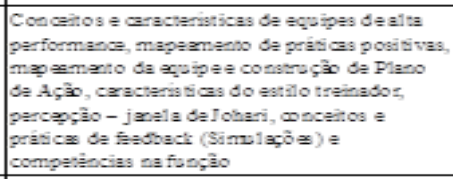 \\
\hline \multirow[b]{2}{*}{ Autogestão } & Men torisg & 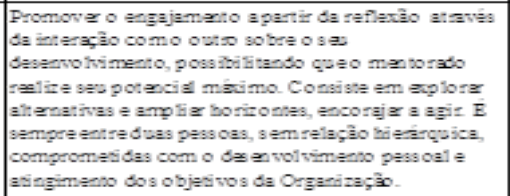 & 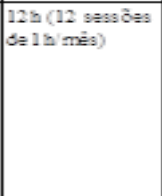 & 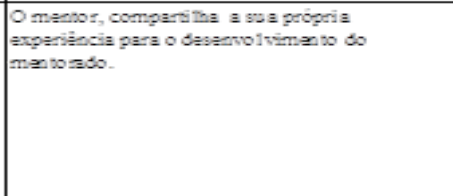 \\
\hline & Coaching & 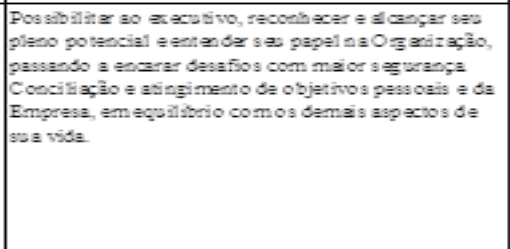 & 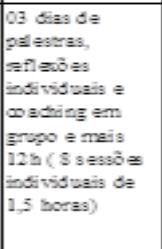 & 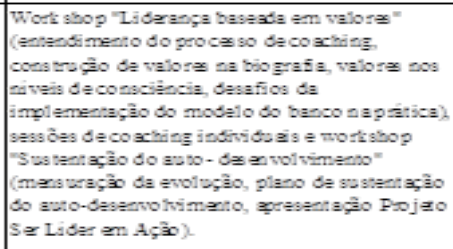 \\
\hline
\end{tabular}

Fonte: elaborada pelas autoras com base nos documentos institucionais, 2011. 
Conforme figura, dos sete programas de desenvolvimento de liderança, a maior carga horária encontra-se no "Ser Líder", para gestores com nível de gerente executivo e acima, atuando em níveis estratégicos da organização e cujo foco é gestão corporativa e do significado, com total de 162 horas. O segundo maior em carga horária é o Ser Gestor I, para gestores no início da função, que abrange funcionários com nível de média gerência e acima e cujo objetivo é ampliar o conhecimento de gestão e o alinhamento com as expectativas de resultado do grupo.

Em seguida está o programa de coaching, voltado ao mesmo público-alvo do programa Ser Líder, com carga horária de 36 horas e cujo objetivo principal é reconhecer o potencial do líder, entender seu papel na organização e trazer reflexões no trabalho de conciliar os objetivos pessoais com os da organização.

Partindo-se da visão dos programas quanto à carga horária e comparando objetivos, público-alvo e conteúdo, nota-se o foco da organização no desenvolvimento de líderes com posição mais estratégica (Ser Líder), buscando o reforço do "modelo" de cultura do banco por meio das ações cotidianas. A expectativa do banco portanto, é que as ações coordenadas em torno dos valores e modos operacionais institucionais trarão maiores resultados econômicos.

Complementando o desenvolvimento de liderança, após a prioridade nos níveis mais estratégicos, percebe-se que levando em conta a carga horária, o segundo é a formação dos gestores recentes na função (Ser Gestor I) por meio de temas mais aplicados ao diaa-dia da equipe e a ênfase nas técnicas e práticas de gestão menos operacionais - uma vez que processos de RH é o conteúdo abordado no Ser Gestor Básico.

A análise da documentação aponta para a complementaridade entre os blocos. $\mathrm{Na}$ autogestão o foco é trazer o desenvolvimento para o auto-conhecimento, potencial individual, alinhamento entre objetivos pessoais e organizacionais. É o trabalho das competências individuais, aderência à cultura do grupo e engajamento para atuação na gestão da equipe.

Na gestão das relações, o conteúdo é voltado para a atuação do líder com a equipe, lidando com demandas operacionais da gestão, como também de práticas de liderança para direcionar o grupo aos objetivos da organização.

A gestão corporativa e do significado tem o programa direcionado a preparar o líder para atuar como protagonista e exemplo disseminador do modelo do banco, engajador de ações corporativas e guardião da cultura organizacional por meio da liderança.

Ao analisar em especial os dois programas mais extensos e considerados prioritários para a organização, nota-se similaridade de objetivos. Dos sete programas, somente estes dois abordam claramente a liderança como uma condição para resultados e sua atuação no dia-a-dia. Em ambos e somente nestes dois aparecem as palavras: dia-a-dia e resultado. São programas voltados para que a liderança, tanto em níveis estratégicos quanto em seu início de carreira, esteja preparada para lidar com as questões e desafios do dia-a-dia (a organização deixa claro o quanto espera que o líder atue como protagonista do modelo do banco como também resolva os problemas) e tenha a atenção não apenas no caminho para o alcance de objetivos da organização - podendo ser entendidos como mensuráveis ou não, qualitativos ou quantitativos, mas que tenha o foco voltado para o crescimento do resultado.

Em síntese, a organização busca conduzir seus programas para que sejam assertivos na formação e condução do líder, para as práticas e comportamentos que trarão maiores resultados econômicos para a instituição. 


\section{Considerações sobre a prática da liderança}

No estudo dos programas institucionais oferecidos pelo banco para atrair talentos, desenvolver potenciais e reforçar cultura, identificou-se que dos sete existentes quatro são voltados à identificação e formação de novos líderes da organização. Evidenciase nestes quatro a similaridade nos objetivos: desenvolver os valores e as condutas consideradas eficazes pelo banco.

De acordo com os programas examinados, aqueles voltados ao desenvolvimento de liderança estão agrupados em três categorias: autogestão, gestão das relações pessoais e gestão da estratégia, direcionando e dando prioridade ao alinhamento da liderança com a atuação no modelo do banco e a contribuição para o resultado. A instituição propicia ao líder autoconhecimento, desenvolve-o para gerir pessoas (lidar com a diversidade e complexidade) e exige comprometimento com as metas institucionais. Ao líder, não basta obter que o grupo atinja metas, mas que o faça nos parâmetros da cultura institucional, replicando o modelo de valores e condutas.

Ao analisar os blocos dos programas à luz das teorias de liderança, vemos que o programa de autogestão trabalha o sentido que as pessoas atribuem ao trabalho, liderar e ser lideradas, identificar o que as motiva e o alinhamento destes motivos com os propósitos do banco. As práticas do programa de autogestão procuram motivar, criar identificação entre o indivíduo e a instituição e transformar valores individuais para os alinhar com os institucionais.

No bloco de gestão das relações o objetivo é aumentar o conhecimento dos gestores sobre liderança e adicionalmente, trabalhar as práticas cotidianas na condução dos desafios da organização e da gestão da equipe. O bloco remete ao desenvolvimento de liderança contemporânea no viés da formação para que os líderes sejam vistos como indivíduos que inspiram seus seguidores por meio de palavras, ideias e comportamentos, na linha da teoria situacional. Está em pauta a motivação dos liderados.

Nos dois programas com maior carga horária e prioritários (Ser Líder e Gestor I), nota-se similaridade de objetivos. Dos sete programas, somente estes dois abordam claramente a liderança como instrumento de resultados e de atuação no dia-a-dia. São programas voltados para que a liderança, tanto em níveis estratégicos (Ser Líder) quanto em seu início de carreira (Ser Gestor I), esteja preparada para lidar com os problemas cotidianos (a organização deixa claro o quanto espera que o líder atue como protagonista do modelo do banco como também resolva os problemas) e tenha a atenção não apenas no caminho a percorrer, mas que tenha o foco para o crescimento do resultado.

A organização busca programas assertivos na formação e condução do líder em seu dia-a-dia, considerado responsável por replicar e ensinar valores e condutas do banco. O líder deve ser o protagonista na execução, engajamento de equipes e áreas e no reforço do modelo de atuação. Para isso oferece programas de autogestão, propicia ferramentas de auto-conhecimento e alinhamento dos objetivos pessoais com os organizacionais, trabalhando a identificação pessoal com o modelo organizacional. Em paralelo, prepara-o para a efetividade e sucesso na gestão das relações, meio pelo qual conduzirá seus liderados aos objetivos e metas.

Quando o líder ocupa uma posição estratégica, o programa de capacitação busca desenvolvê-lo para aplicar o modelo do banco, tendo como expectativa que trabalhe para o engajamento e a criação de valor presente e futuro, gerando resultados que contribuam para que o banco torne-se uma liderança no setor e referência na sociedade. 


\section{PUC-SP}

De acordo com os programas de capacitação examinados, o desenvolvimento de liderança compreende os três principais elementos das chamadas abordagens teóricas sobre liderança. Seleção de pessoas (e seus traços ou personalidade, ainda que não haja uma classificação explicita dos traços ideais à liderança); ensino e aprendizagem de condutas, valores e práticas, e entre essas práticas, as da motivação e do controle, ambas imprescindíveis para a obtenção de metas e reprodução do modelo do banco quanto à gestão de pessoas; autoconhecimento como condição para adaptação às inexoráveis variações do contexto ou situação. A prática do desenvolvimento da liderança aponta para a complementaridade das muitas "teorias".

\section{Referências Bibliográficas}

AMORIM, M. C. S. e MARTINS, R. H. P. Poder e liderança, as contribuições de Maquiavel, Gramsci, Hayeck e Foulcault. In: XXXI ENANPAD, 2007, Rio de Janeiro. XXXI ENANPAD. Rio de Janeiro: ANPAD, 2007.

BERGAMINI, C. W. Liderança - administração do sentido. $3^{a}$ tiragem, SP: Atlas, 1994. BERGAMINI, C. W., \& CODA, R. Psicodinâmica da vida organizacional: Motivação e liderança. $2^{\mathrm{a}}$ ed. São Paulo: Atlas, 1997.

DUPUY, J. P. Nas origens das ciências cognitivas. SP: UNESP, 1996.

FOUCAULT, M. Microfísica do poder. 11ª reimpressão. Rio: Graal, 1979.

HERSEY, P. BLANCHARD, K. Psicologia para administradores - a teoria e as técnicas da liderança situacional. SP: EPU, 1986.

LIMONGI-FRANÇA e ARELLANO. Ana C. e Eliete B. Liderança, poder e comportamento organizacional. IN: FLEURY, Maria T. Leme (org.) As pessoas na Organização. Ed. Gente, SP 2002, p.259-269.

ROBBINS, S. P. Comportamento Organizacional. SP: Prentice Hall, 2005.

SENNETT, R. A corrosão do caráter - consequências pessoais do trabalho no novo capitalismo. Rio: Record, 2002.

VERGARA, S. C. Gestão de pessoas. São Paulo: Atlas, 1999. 